Nature, Science \& Technology

Research Article

\title{
Corporate Social Responsibility And Sustainability: A Perspective From The Oil And Gas Industry
}

\author{
Ankit Duttagupta ${ }^{1}$, MD Maksudul Islam ${ }^{1}$, Emad Rabiei Hosseinabad ${ }^{2}$, Muhammad Adib Uz Zaman ${ }^{3 *}$. \\ ${ }^{1}$ University of Minnesota Duluth, Duluth, MN 55812, USA \\ ${ }^{2}$ Northern Illinois University, Illinois, USA \\ ${ }^{3}$ Texas Tech University, Lubbock, TX 79409, USA
}

\section{Keywords}

Corporate social responsibility, Sustainable development, Economic impact, Operations, Corporate strategy

\begin{abstract}
Corporate social responsibility (CSR) is an extension of the corporate role which encompasses the economic, legal, ethical, and philanthropic responsibilities that a company must fulfill, such that it improves the overall quality of life of the community around it. Sustainable development (SD) on the other hand involves operations that have a minimal impact on the environment. However, in today's global environment, governments around the world are implementing stricter environmental regulations and supporting higher standards of living for their citizens. This socially and environmentally conscious undertone has made it imperative for organizations to address issues related to CSR and SD seriously and in many cases with the highest urgency. Successful implementation CSR and CS strategies are very vital for oil and gas industries due to fact that these industries are very responsible for the global environment as well as these companies represent the top wealthy industries of the world. The three oil and gas industries (Shell, BP, and Total S.A.) that have been analyzed in this project work, demonstrate that their CS and CSR strategies are not the same and there is scope of improvement. From the comparative analysis, BP's investment $(0.8 \%$ of the net annual profit) in community development is very low compared to the investment in community development of Shell (5.5\% of Net annual profit) and Total S.A. (4.77\% of Net annual profit) which clearly indicates that BP's CSR strategies are not sustainable also BP's TBL aspects are not balanced in this case.
\end{abstract}

\section{Introduction}

Corporate social responsibility (CSR) can be described as a managerial concept that recommends environmental and social policy practices into a company's planning and operations. Since balancing CSR and SD has become such a mandatory business standard for today's organizations irrespective of their field and market of operation, it is decided to focus our study on understanding the various strategies implemented by oil and gas companies with regards to the matter. Through this paper, not only do the CSR and SD strategies undertaken by three major oil and gas corporations, namely Shell, British Petroleum (BP) \& Total are reviewed, but also are intended to understand and carry out an analytical evaluation and comparison of the overall effectiveness of their efforts in finding the perfect balance between the CSR and SD. Finally, we conclude the paper by putting in recommendations for prospective engineering managers in each of the above-mentioned companies, with the expectation that these recommendations will help the above companies improve on the impact of their respective CSR and SD activities, even though they operate in a field of business that is extremely complicated and prone to environmental hazards. Therefore, it has become critical for organizations to pair sustainable development with corporate social responsibility, with the latter being considered as one of the key inputs to achieving the former [1].

For the reviewers to follow through the different segments of the paper, the paper is organized in the following format:

- Understanding corporate social responsibility - focuses on the present-day definition of corporate responsibility and its salient features and intentions.
- Understand sustainable development - focuses on the present-day definition of sustainable development and the various expectations surrounding it.

- Understand the relationship between them - discusses the link between the two and how any one of them is affected without the proper implementation of the other.

- Review and understand the various strategies implemented by Shell, BP and Total to balance CSR and SD - discusses the current strategies applied by the above mentioned to address the need for CSR and SD.

- Review and compare the strategies implemented by each of the three companies - analytically compare the strategy of each company, in the pursuit of finding probable strategy gaps that can be addressed.

- Review and analyze the problems that have had an impact on the effectiveness of the strategies - evaluate the barriers that impede the effectiveness of the overall company's CSR and SD strategy.

- Probable suggestions to improve the effectiveness of the strategies implemented - provide recommendations for prospective engineering managers to help them effectively balance the CSR and SD activities.

\section{Corporate social responsibility and organizations}

2.1. Understanding Corporate Social Responsibility for Organizations

With the onset of the winds of social change, developed societies have seen a drastic rise in consumer activism, mobility, and the need for corporate accountability [2]. Companies today face an ever-increasing 
demand to be socially responsible, not only towards their preferred customers, but also to the overall community they operate in. They face a steep path to balancing their social duties and responsibilities as well as their commitment to investors who place relentless pressure on them to maximize short-term profits during very volatile economic times. However, those companies that build and apply their social responsibility policies strategically, are on a much safer path to fulfilling their commitments to the society who play an important role in the availability of human resources as well as to their investors by reaping profits indirectly from the goodwill and social growth they promote.

According to the International Standards Organization (ISO) 26000 CSR is defined as the responsibility of an organization to the society it operates in, with respect to its business decisions and activities. It lays down the guidelines for an organization's social responsibility with regards to the core areas of human rights, labor practices, environmental practices, fair operating practices, consumer issues, and community development, such that in the race for attaining higher profits, corporate organizations do not go astray on their mandatory commitment to the welfare of the environment and the people they work with and serve. To put the above in practice, the ISO 26000 has provided some guidelines that organizations are expected to use to evaluate their behavior [3]. They are briefly discussed and are as follows (International Standard Organization, 2010):

1) An organization should be accountable for its impacts on society, the economy, and the environment

This principle recognizes the importance of the positive impact on the environment and the society that organizations are expected to have through being directly held accountable for their actions. This principle also holds them accountable for any negative impacts that may occur and requires them to take effective steps within a certain period such that any unintended and unforeseen repetition of those negative impacts can be mitigated.

2) Any organization should be responsible to clarify its impact on environment and society.

This principle requires organizations to be transparent with regards to the actual intention behind their economic activities and the various decisions taken to ensure that under no circumstances social and environmental issues are not compromised. To ensure that companies are held true to their word, the principle also urges companies to disclose performance data on relevant and significant social issues.

3) An organization should behave ethically.

This principle urges organizations to practice ethical behavior in al their commercial and non-commercial activities. It urges companies to not only observe their own organizational practice of ethics, but also urges them to promote ethical behavior in the environments they operate in thus extending to fair treatment to man and animals alike.

4) An organization should respect, consider, and respond to the interests of its stakeholders.

The above principle encourages organizations to look beyond the interests of the owners, members, and the customers they serve, thereby also including the interest of the members whose lives they might indirectly or directly affect, even though they are not attached with the operating organization. This principle is aimed at helping organizations to effectively formulate their decision-making process, keeping the wide array of stakeholders into perspective.

5) An organization should accept that respect for the rule of law is mandatory

This principle is aimed at reminding organizations, that they are not above the law and therefore must strictly abide by all the legal regulations set within the jurisdictions in which they operate. It also urges organizations to periodically review their compliance standards, thus protecting themselves from defaulting on any applicable legal obligations.

6) International norms, behavior and rules of law should be acknowledged and respected by an organization.

This principle is aimed at guiding organizations in their overall conduct when operating in areas where the rule of law might not provide adequate environmental and social safeguards. It urges organizations to show restraint and follow international norms and behavior even if other organizations operating within that environment exhibit a clear disregard for interactions CSR practices.

7) An organization should respect human rights and recognize both their importance and their universality.

This principle forms the backbone of corporate social responsibility, thereby urging corporations to always promote and respect the rights listed in the Bill of Human Rights, even in circumstances where there are deliberate and blatant violations of the human rights without any plausible legal consequences.

As the masses grow more informed and conscious about corporate accountability with respect to their immediate surroundings and the environment, it has been seen that organizations who practice and preach the above-mentioned principles, see a positive rise in their overall economic competency. Figure 1 below, clearly depicts that in today's day and age even hardnosed investors prefer to invest in organizations that show a healthy amount of commitment and concern towards their overall social responsibility.

\section{Investors}

Which one of the three companies below would you most likely invest in? (\% respondents)

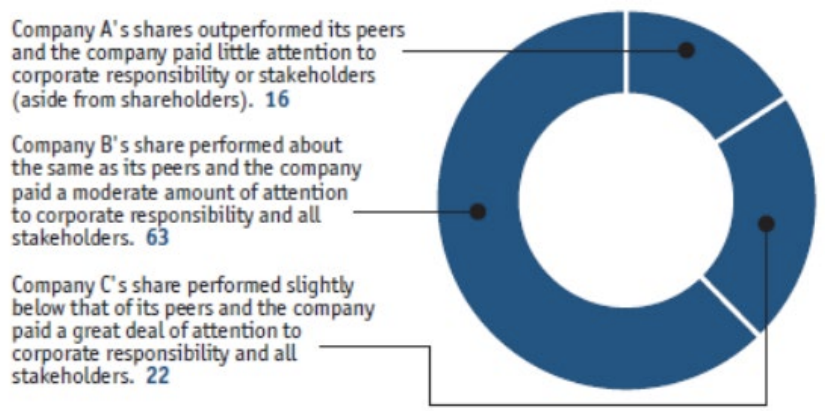

Figure 1. Investors preferences with regards to CSR [4]

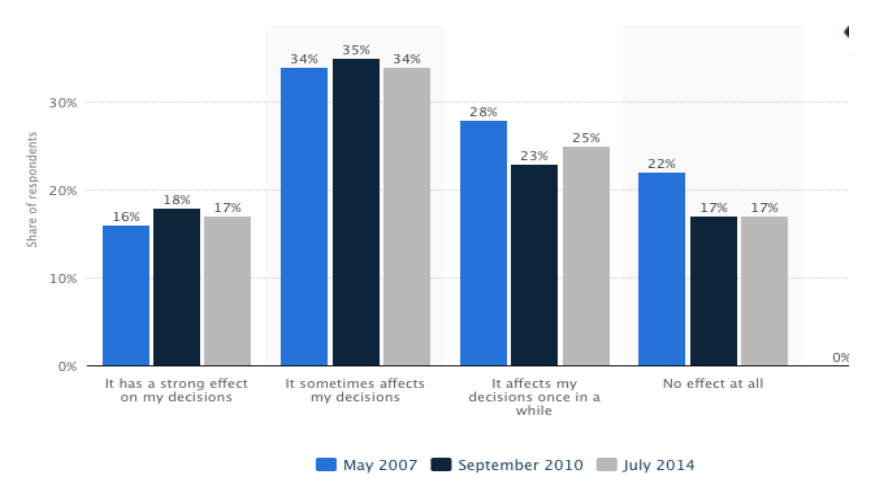

Source: Statista.com

Figure 2. Customer preferences with regards to CSR

The advantages of being socially responsible are not only limited to potential investors. As shown in Figure 2, customers today pay close attention to the activities of the organizations that they buy their 
products from. In the year 2014, nearly $34 \%$ of customers claimed that their decision to buy a product from a certain company was directly based on the company's performance with regards to their commitment to the community as a whole. The above figures were added to support the idea, that organizations must make corporate social responsibility a priority in this day and age. Gone are the days when economic profit could only be reaped from the internal operations within the company and showing little or no regard for the environment or for that matter, the lives who supported the operations. Organizations today, must strategically develop their CSR policy because ignorance regarding the matter can not only hurt an organization's bottom line but can also cause irrepairable damage to their reputation.

\subsection{Understanding Corporate Sustainability for Oil and Gas Organizations}

Corporate sustainably is a buzzword for today's business organization. Statistically, 93\% [5] of chief executive officers of the world believe that it is impossible to sustain a competitive benchmark without incorporating sustainability. Corporate sustainability can be defined by World Commission on Environment and Development [6], "meeting the needs of the present generation without compromising the ability of future generations to meet their needs" and this definition illustrates that organizations are vulnerable to sustain in the future without caring the environment. In today's world, all companies must have effective sustainable strategy especially in oil and gas companies [7] because these organizations often fail to fulfill the triple bottom line (TBL Figure 3) of a sustainable strategy. The triple bottom line of sustainable strategies is the aggregate consideration of economic, social, and environmental factors and the corporate context of this TBL [8] is so important that without an effective TBI plan today's oil and gas companies cannot run their business. This TBL concept signifies a condition in which organizations combine their economic goals with the taking of responsibility for their impact on eco-systems and human beings [9]. Organizations are facing the contest of implementing state-of-the-art sustainability strategy implementation due to fact that corporate sustainability has taken the core of business success [10]

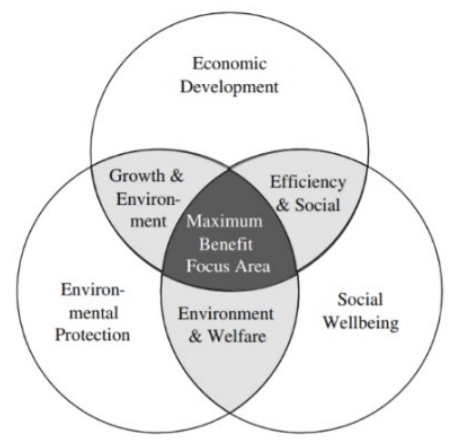

Figure 3. Triple bottom line of sustainability [11]

Although oil and gas companies have large portion of wealth among the world's major industries; their efforts toward sustainability still require improvement [12]. Oil and gas drills include hazardous activities, and these are normally not environment friendly because of the nature of hazardous actions (exploration, drilling, extraction, storage, shipping, refining, selling and distribution of the product). Thus, oil and gas companies provoke high risks and oil businesses are compelled to work continuously for reducing adverse impacts on the environment and people [12]. There are a lot of hazardous incidents like the Santa Barbara oil spill in 1969 in California and Deep-Water Horizon disaster in the Gulf of Mexico in 2010, which are documented as lack of environmental, health and safety (EHS) efforts and progress toward sustainability in the oil and gas sector [13]. In 2003, local people in Ecuador charged a lawsuit against Chevron for the environmental pollution of Amazon rainforest [13]. Moreover, corporations in the oil and gas sector were in a vulnerable position regarding major environmental and human rights controversies. For instance, the operations of Shell Company in Nigeria (in 1990) were responsible for the contamination of the river and endangered the native people of the Ogoni area [13].

In this work, the discussion revolves around the three oil and gas companies which are Shell, British Petroleum (BP) and Total S.A. For analyzing the sustainability strategy of these three renowned companies, we will focus on three common management issues which are environmental management (managing waste, managing air emissions and spills), health management and safety management (energy and process control issues, training of personnel, human injuries, and incidents). On the same time, it will be analyzed how these companies maintain their competitive benchmark by incorporating corporate social responsibility with their sustainable strategies.

\section{The relationship between Corporate Social Responsibility and Corporate Sustainability}

CSR and Corporate Sustainability (CS) is very similar and can be thought of as the two sides of the coin [14]. CSR intends to leverage synergies between the firm and various stakeholders to create transparency and a mutually beneficial partnership that helps organizations to become more sustainable. Moreover, environmental sustainability is an important consideration for many firms because this increases brand value. If a firm meets environmental and typical social aspects of CSR, both stakeholders and shareholders will prefer it. The term CSR first came from the prospective of business focusing on social matters. On the other hand, sustainable development emerged from the environmental protection debate at the UN Earth Summit in Rio de Janeiro in 1992 [15]. Before 1990, there was lack of effective business models to incorporate sustainability in the organization [15]. The Erasmus University's Business Society Management proposed CS as the goal, incorporating CSR as an intermediate stage while both concepts would balance into the triple bottom line i.e people, profit, and planet (Figure 4) [16].

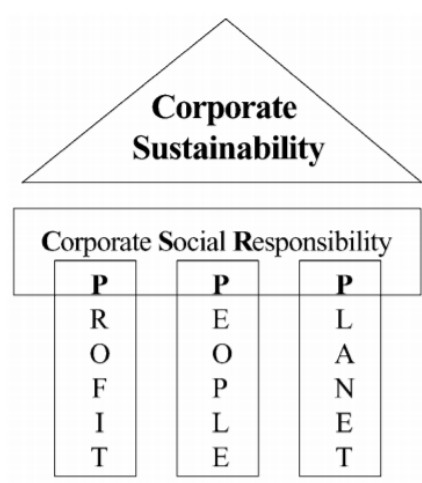

Figure 4. Relationship between CS and CSR [16]

(Ebner \& Baumgartner, 2006) recommended that CSR is a fundamental element of corporate sustainability and using CSR as a social strand will help to build transparency and good relationship among stakeholders and society. A framework [1] based on Brundtland's Sustainability model focusing on the triple-bottom-line (Figure 5) was proposed.

Now that the importance of CSR and SD in the present-day society and the crucial relationship that exists between them, is highlighted, it should be realized that the above discussion is applicable to any industry, including risk prone and complex businesses like oil and gas industries. Their ability and need to operate in multiple societies practicing different norms and behaviors and their proximity to 
crucial ecological systems, subjects them to critical scrutiny on their CSR and SD practices and therefore it is even more important that we focus on their strategies with regards to the matter.

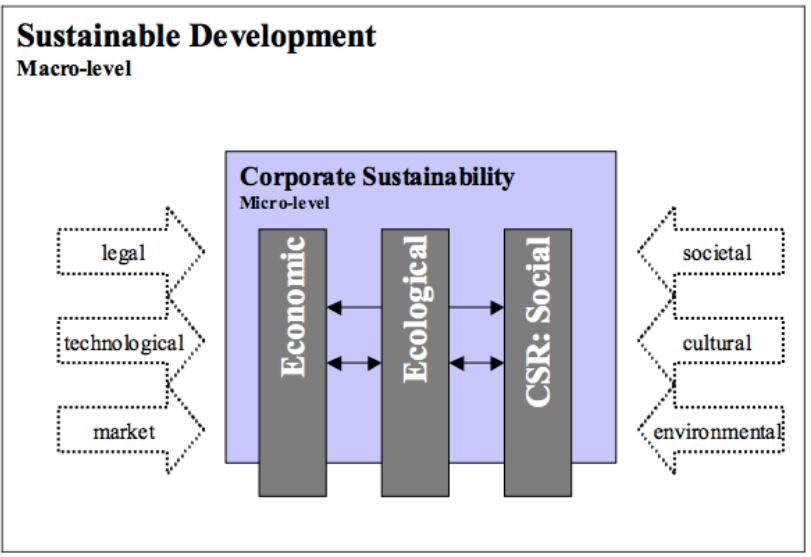

Figure 5. Relationship between Corporate sustainability and CSR [1]

\section{Corporate Social Responsibility and Sustainable} Development strategy: Royal Dutch Shell (Shell)

Company Profile: Royal Dutch Shell is among the world's largest oil and gas company. With operations in seventy different countries, extending across all seven continents, Shell is among the leading companies in terms of market capitalization, operating cash flow and oil and gas production capacity. They serve around 25 million customers worldwide through a global network of 43,000 retail sites and 93,000 employees [17-18]. For the year 2015, their overall revenues stood at a staggering $\$ 264.96$ billion [17]. Figure 6 shown below is aimed at providing a general overview of the operating and organizational structure of the company.

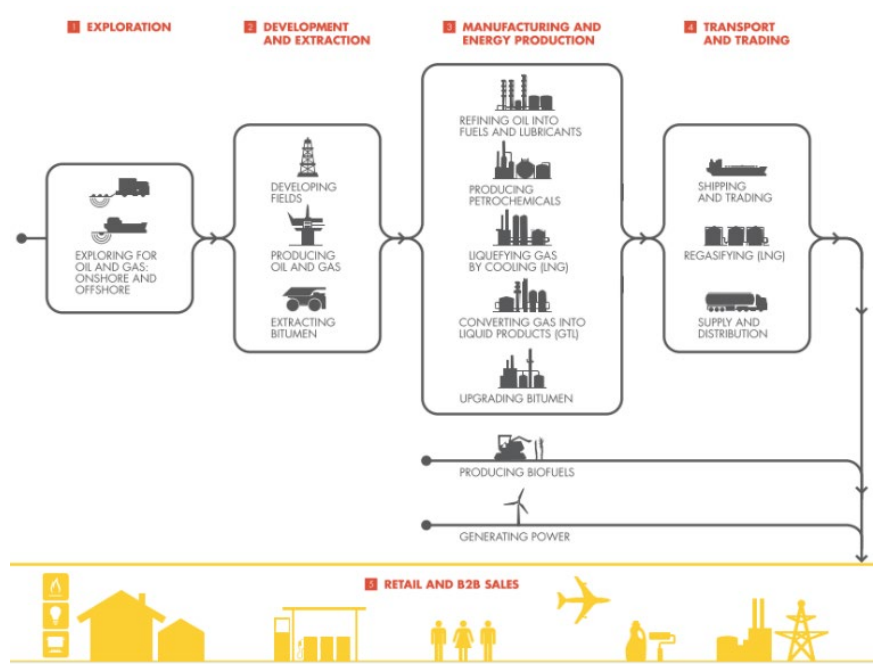

Figure 6. Shell operating and organizing structure [17]

Company Strategy for Effective CSR and SD: To build up its reputation as an organization that cares not only about profits, but also about the well-being of the people it serves and the environment it operates in, Shell employs a strategic plan to integrate the aspects of both CSR and $\mathrm{SD}$ in daily routine operations. They are as follows [18]: i) Helping to shape a more sustainable energy future

The organization recognizes and realizes the grave impact of climate change caused due to man-made activities and thus, has decided to not only support the action called by governments and energy customers alike, but also invest in large scale commercial technologies with an emphasis on lower carbon footprints such as natural gas, advanced biofuels, and solar energy. The company is also a signatory member of the zero flaring policy and maintains an internal price of $\$ 40$ per ton of greenhouse gases emitted by its operations with regards to the carbon price initiative.

ii) Sharing wider benefits where we operate

The organization is pushing for open dialog within the communities it serves. To address the development of local economies by creating jobs and sourcing raw materials from local suppliers, Shell is poised to address critical concerns with regards to its commitment to the economic prosperity of the society.

iii) Running a safe, efficient, responsible, and profitable business

Shell realizes that at the core of its operations are the people and the communities who make it possible for them to operate smoothly on a day-to-day basis. Thus, the organization has committed itself to continuously developing and improving safety standards and environmental management plans by keeping track of their performance through a range of dedicated metrics such as social investments made and community complaints addressed.

iv) Extensive external collaboration with organizations and experts to gain valuable insights

Shell understands that to be effective in its execution of CSR and SD activities, the organization must look beyond its capabilities and bring in experts from outside even if some of them do not agree with their overall sustainability framework. The collaborations are aimed, not only at understanding the different points of disagreement such that a resolution can be achieved amicably among both parties but also to share knowledge and experience regarding continuous improvement practices among each other.

\section{v) Maintains a balanced scorecard structure}

To translate the organizations strategic objectives with regards to CSR and SD, Shell maintains a balanced scorecard which allows them to measure the effectiveness of their policies through a coherent set of performance metrics. The scorecard allows the management at shell to keep track of improvements. As of 2015, the Shell Executive Committee ensured that its initiatives in CSR and SD were effectively split between sustainable development (20\%), operation excellence (50\%) and cash flow from operating activities (30\%).

\section{Corporate Social Responsibility and Sustainable Development strategy: British Petroleum (BP)}

Company Profile: British Petroleum is ranked 6th among the world's largest oil and gas companies. With operations in seventy different countries, extending across all seven continents, BP is among the leading companies in terms of market capitalization, proven reserves, and oil and gas production capacity. They serve around 8 million customers worldwide through a global network of 17,000 retail sites and 80,000 employees [19-20]. For the year 2015, their overall revenues stood at a staggering $\$ 227.9$ billion [19]. Figure 7 shown below is aimed at providing a general overview of the operating and organizational structure of the company.

Company Strategy for Effective CSR and SD: Unlike Shell, BP has a much more focused strategy towards its role as a valuable partner in social responsibility and sustainability. Their activities are focused on reducing the carbon footprint of their operations, investing in innovation leading to safer drilling practices, extending the principles of human rights to their external corporate stakeholders, and supporting legislation that focuses on environmental conservation. The above-mentioned topics are discussed in greater detail below [19]: 


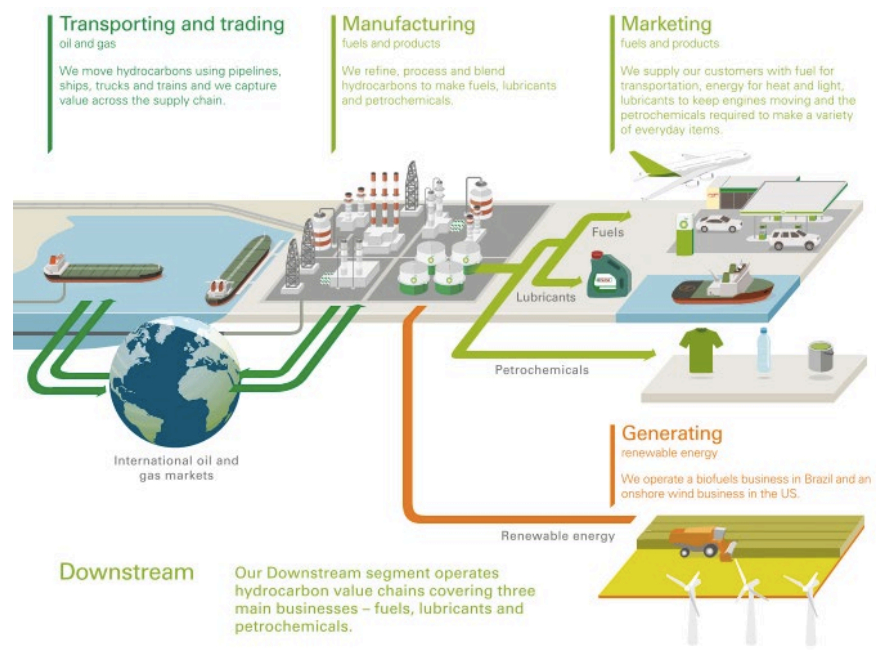

Figure 7. BP operating and organizational structure [19] i) Active participation in the Carbon Pricing leadership coalition

By bringing together senior representatives from the government and private sector organizations, BP supports the curb on the emission of greenhouse gasses by proposing a penalty on $\mathrm{CO}_{2}$ emissions. Using and internal price of $\$ 40$ per ton of $\mathrm{CO}_{2}$ emitted, $\mathrm{BP}$ wants to place in a policy that prioritizes the reduction of greenhouse gases among businesses and consumers alike through a well-constructed carbon cap and trade system.

\section{ii) Investing in a low carbon future}

By investing substantial resources in the production of sugar cane ethanol and wind energy, BP has aggressively tried to reduce its carbon footprint by 0.7 million tons which is equivalent to the carbon produced by 334,000 European cars. It also considers itself as one of the top producers of wind energy in the United States of America, with heavy investments in 16 wind farms across the country. With 1,556 megawatts of electricity generated through this initiative, BP expects to have reduced its carbon footprint by 2.7 million tons in the year 2015.

iii) Actively support the World Banks's zero routine flaring by 2030 initiative

As a founding member of the World Bank's Global Gas Flaring Reduction partnership, BP actively endorses the elimination of routine flaring from oil assets by the year 2030. Flaring is the controlled burning of natural gas or waste gas during production, refining and manufacturing operations. Even though controlled and necessary, this combustion contributes significantly to greenhouse gasses and therefore needs attention.

iv) Implementing the practice of following human rights principles across all its suppliers

As a supporter of the International Bill of Human Rights and the International Labor Organization's Declaration on Fundamental Principles and Rights at Work, BP has made aggressive amendments to its policy regarding its interaction with communities and employee awareness. Using contractual commitments for its internal and external corporate stakeholders, BP ensures that under no circumstances, the company is directly or indirectly indicted for a violation of human rights, not only outside its realm of operations but also within the organization itself.

v) Invest in safer drilling practices

To prevent a repetition of its deep-water horizon incident in the Gulf of Mexico, BP has taken active measures to organize centralized teams focusing primarily on the drilling practices of its deep water and onshore oil fields. By incorporating the use of advanced and innovative technologies coupled with guidance and independent assessment of industry experts, BP has tried to protect its interests by preventing incidents throughout the life cycle of its operational wells.

\section{Corporate Social Responsibility and Sustainable Development strategy: Total Société Anonyme (TSA)}

Company Profile: TSA is ranked 4th among the world's largest oil and gas companies. With operations in 150 different countries, extending across all seven continents, TSA is a world leader in terms of market services provided, refinement of chemicals and oil and gas production capacity. They serve around 4 million customers worldwide every day through a global network of 15,569 retail sites and 100,000 employees [21-22]. For the year 2015, their overall revenues stood at $\$ 165.4$ billion [22]. Figure 8 shown below is aimed at providing a general overview of the operating and organizational structure of the company.
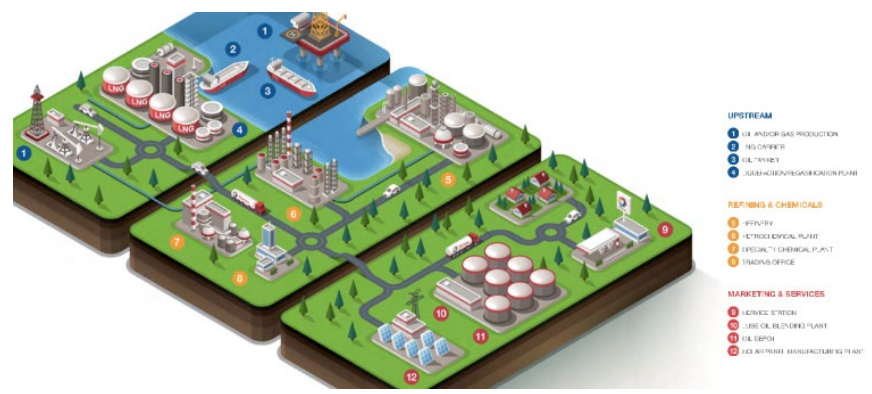

Figure 8. TSA operating and organizational structure [21]

Company Strategy for Effective CSR and SD: Like BP, Total has an ambitious plan to reduce the emission of greenhouse gasses by controlling its carbon footprint. Their core strategy involves the increase in the production of more low carbon content fuels such as natural gas and other renewable sources of energy such as solar. The strategy also takes into consideration, the company's overall commitment to improving the lives of people in the areas where it operates along with supporting initiatives to control flaring and global legislation with regards to the oil and gas industry. The abovementioned topics are discussed in greater detail below (Total S.A., 2015)

\section{i) Promote the use of natural gas}

Owing to a low carbon content, TSA is aggressively trying to reduce the impact of its carbon footprint by concentrating on the production of more natural gas than oil. As of $2014,50 \%$ of the company's overall production included natural gas with an ambitious strategy to double its current capacities for liquefied natural gas by 2017.

ii) Develop renewable energies, including solar

Owing to its position as a majority stakeholder in SunPower, the organization is ranked 2nd in the world with regards to revenue earned from being a solar operator. In a bid to aggressively push away from high carbon content fuels, TSA hopes to maximize SunPower's cell manufacturing capability by three times in the next five years.

\section{iii) Enhance energy efficiency}

In another effort to reduce carbon emissions, the company has introduced over 70 products and services under its Total Ecosolutions brand name. Total Ecosolutions focuses on helping customers reduce their carbon footprint by promoting biodegradable products, energyefficient buildings, and efficient use of energy resources. As of 2014 this initiative has managed to reduce carbon emissions by 1.5 million metric tons. TSA also supports zero flaring by 2030 initiative under this program and has actively stopped flaring activities on all new oil and gas projects starting 2000.

iv) Facilitate access to sustainable energy

To influence and improve the lives of millions of people in Africa and Asia through sustainable sources of energy, the company has set an ambitious target to introduce and sell Awango solar lamps, to more than 25 million people by 2020 . 


\section{v) Support International Initiatives}

Touting itself as a responsible player in the oil and gas industry, TSA not only encourages other organizations operating in the oil and gas sector to work together, but it also works with its internal and external stakeholders to meet the guidelines set by the government and United Nations (UN) agencies. It actively supports the carbon price penalty propagated by the UN and organizations like BP and maintains an internal price of $\$ 26$ per metric ton. It also actively supports the control of methane gas and flaring activities during the production of its oil and gas.

\section{Findings and Comparative strategy analysis}

Comparing the CSR and SD strategies employed by each of the three companies discussed above, all three of them have a different way of addressing the situation with certain overlapping areas. Based on a thorough analysis of the sustainability report issued by each of the companies, Shell has a very structured approach to addressing CSR and SD issues. At the same, it would be fair to say that the strategy it practices is also the broadest and the most transparent among the three. BP on the other hand addresses the issue of CSR and SD from a more legislative angle, thus trying to raise awareness by endorsing and championing the implementation of regulations which curbs the emission of greenhouse gasses and works for the overall improvement of efficiency within the oil and natural gas industry. TSA operates on a very similar strategic framework as BP's, thereby laying a lot of emphasis on the reduction of the emission of greenhouse gasses by investing heavily in low carbon content fuels.

One interesting observation was that only Shell was transparent with regards to actively releasing value it places on its CSR and SD operations through the public release of its organizational score card. This allowed us to gauge as to how seriously Shell takes the issue of CSR and SD and how effectively it tracks its improvement on the matter. Neither BP nor TSA released an organizational score card, thereby preventing us from clearly understanding the emphasis it received within their respective organization.

With regards to the reduction of greenhouse gases, all the three companies have taken active steps to invest further in renewable sources of energy such as solar and wind power. A substantial investment has also been made in increasing the overall production of natural gasses as well. However, one very interesting observation was that even though all three companies are a following member of the carbon pricing initiative, which is aimed at being a deterrent in controlling the high emissions of greenhouse gases. TSA has an internal price of $\$ 26$ per ton of emissions as opposed to BP and Shell to screen their projects using an internal price point of $\$ 40$ per ton. This major discrepancy in internal price points almost raises the question that there is not fixed policy with regards to the carbon pricing initiative. It seems like although each of the companies agree with regards to curbing the emission of greenhouse gasses, there is no fixed or standardized penalty for failing to do so. This major in the pricing policy raises grave concerns with regards to the adequacy of the whole carbon pricing initiative. Since TSA screens its project with a lower value, in the event this initiative is converted into a legislation, BP and Shell pay more as compared to TSA for failing to curb their operations dedicated to reducing greenhouse gases.

Lastly BP and TSA are more focused on changing the oil and gas environment around themselves as opposed to working on improving their own operational synergies. Most of their strategies are geared towards legislative changes and how they can render their active support to them. Shell on the other hand, has a more robust internal organizational strategy where it works on improving their process and procedures. This is made clear by their commitment to higher levels of transparency with regards to their internal operations and open collaborations with external partners and experts to assess their organizational improvements. BP and TSA also follow a strategy of seeking expert guidance on matters with regards to CSR and SD, but as shown in Figure 9, unlike Shell, the expert guidance they receive is mostly within the industry and government agencies.

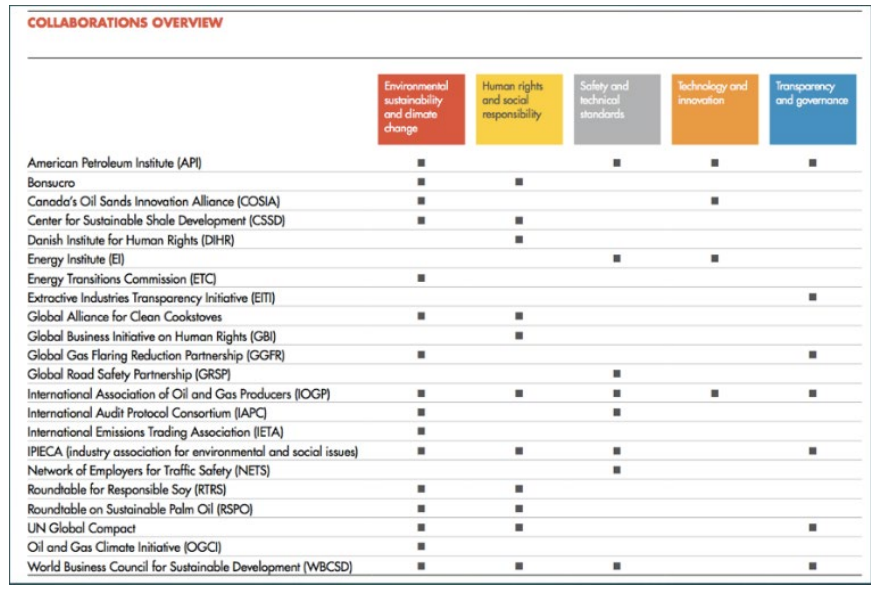

Figure 9. External collaboration: Shell [21]

\section{Barriers to implementation of CSR and SD}

In their search for fossil fuels, oil and gas companies must travel to various parts of the globe and sometimes, these regions that they operate in, might not have the applicable laws or stable and corrupt free governments. In some cases, the regions might be embroiled in civic unrest, thus making it very hard for oil and gas companies to meet the CSR and SD objectives expected of them. In this section, we look at a couple of barriers where oil and gas companies like Shell, BP. and Total must rely on their own judgement with regards to the extent and effectiveness of the CSR and SD activities undertaken by them. The barriers impeding the effectiveness of their existing CSR and SD strategies are as follows [23]

i) The absence of law

For oil and gas companies operating in countries where the standard of the law and environmental regulations are still under development, a dilemma arises with respect to CSR and SD, which oil and gas companies are not expected to address. The perfect example explaining this scenario comes from Shell's operations in Nigeria. Nigeria is blessed with enormous oil reserves, however owing to a very poor enforcement of environmental health and safety regulations coupled with lawlessness and corruption, Shells operation in the country came to be termed as one filled with exploitation and plunder. Even though Shell paid vast sums of royalty to the Nigerian government in exchange for extracting and using its oil reserves, much of the money never trickled down to the lower levels of the society. This created a social environment that was not only violent but affected Shells overall reputation as a responsible extractor and producer of Nigerian oil. To curb the violence and attacks on its infrastructure, Shell is rumored to have supplied the Nigerian security forces with weapons and ammunition and has also taken part in security sweeps along the Niger Delta. The brutal reprisal that followed, dragged the company to court under the pretense of severe violations of human rights. On critically analyzing the above situation, it is very hard to understand as to who is blame. As a result, the cases against Shell were dropped after Shell decided to pay the defendants \$15.5 million dollars in reparation fees and denying any liability with respect to the matter.

ii) Embracing extra-legal standards ill-suited for the business environment

In the absence of clear and stringent regulatory standards, oil and gas companies have been seen to hold themselves to minimum environmental standards set by non-governmental organizations such as the ISO 14000 environmental management system. These standards albeit applicable to some environments might not be suitable to others. Either way it becomes very hard to gauge the behavior of these oil and gas companies since one cannot exactly say that they are not meeting the minimum requirements set by international law, even when they are operating in an environment where meet the minimum standards is simply not enough. A good example of this can be seen in countries where bonded labor is considered as a part of life. An oil and gas company following the minimum standards set by the International Bill of Human Rights can ensure that practices with respect to bonded labor do not occur within 
in premises, but it cannot effectively ensure that its suppliers and contractors are following a similar policy. To address the issue effectively, the company has to go beyond its set threshold and start building and addressing the issue from the grass root levels. In effect it would have to carry out the work, expected to be carried out by the government presiding over the area. This massive effort is clearly beyond the jurisdiction of the oil company and as a result even though it meets the minimum standards for CSR and SD internationally, it is not applicable to the region it currently operates in.

9. Suggestions to improve Corporate Social Responsibility and Corporate Sustainability framework

\section{Suggestions for CS}

- Shell, BP, and TSA must bring in more academic partners on new sustainable oil spill prevention technologies [24].

- BP must work on providing a clear priority list such that it is considered committed to CS.

- These oil and gas companies (specially for BP and TSA) should follow or generate some sustainability assessment tools or frameworks [2527] for understanding the concurrent situation and this will help to detect the gap in the TBL very easily.

\section{Suggestions for CSR}

-All the companies must invest more of their income to CSR activities, specifically BP. Investment on community development will help to increases the brand value of these organizations.

-BP \& Total must follow Shell's approach for effective and transparent partnership with grass root organizations. Shell has turned out a model for BP and Total because its comparative high investment on community development.

-BP must work on providing a clear priority list and effective strategy plan such that it is considered committed to CSR.

\section{Force Field Analysis Model for Shell, BP, and Total SA}

As CS and CSR both demand continuous improvement and organizational changes it will be helpful to describe the impact of these changes through a force field analysis (Figure 10). The more weight of arrows indicates the most significant changes. From the force field analysis, global warning and reducing carbon footprint have become the burning issue for these companies and these three companies investing a lot of money for reducing Green House Gases (GHG) but still now these attempts are demanding huge research collaboration and economic funding. Also, these three oil and gas companies should follow strictly the ISO: 26000 (Guidance on social responsibility) rules to obtain a perfect CSR image.

\section{Recommendations for Engineering Managers of Shell, BP, and Total}

- Engineering managers should emphasize on safety issues as human injuries or fatal accidents will put a negative impact on TBL aspects of sustainability and the company's CSR image. Managers should provide automation or automotive gears for performing highly hazardous tasks. There should be safety barriers in dangerous areas and should be restricted for unnecessary workers. Managers should take necessary steps to perform baseline industrial hygiene survey for determining the safety of every industrial space (Schneider et al., 2015).

- Managers must record previous TBL reports and assess recent TBI conditions to understand the gap among economic, social, and environmental factors. The manager should take the necessary steps to maintain the balance of three aspects. If need, the manger should generate or follow any sustainability framework or indices to do his operation promptly. He must interpret previous and recent results for giving dynamic solution and decision making for an emergency.

- To prevent the damage of oil spill, mangers can take initiative for further research on developing sustainable contrivances against oil spill [24].

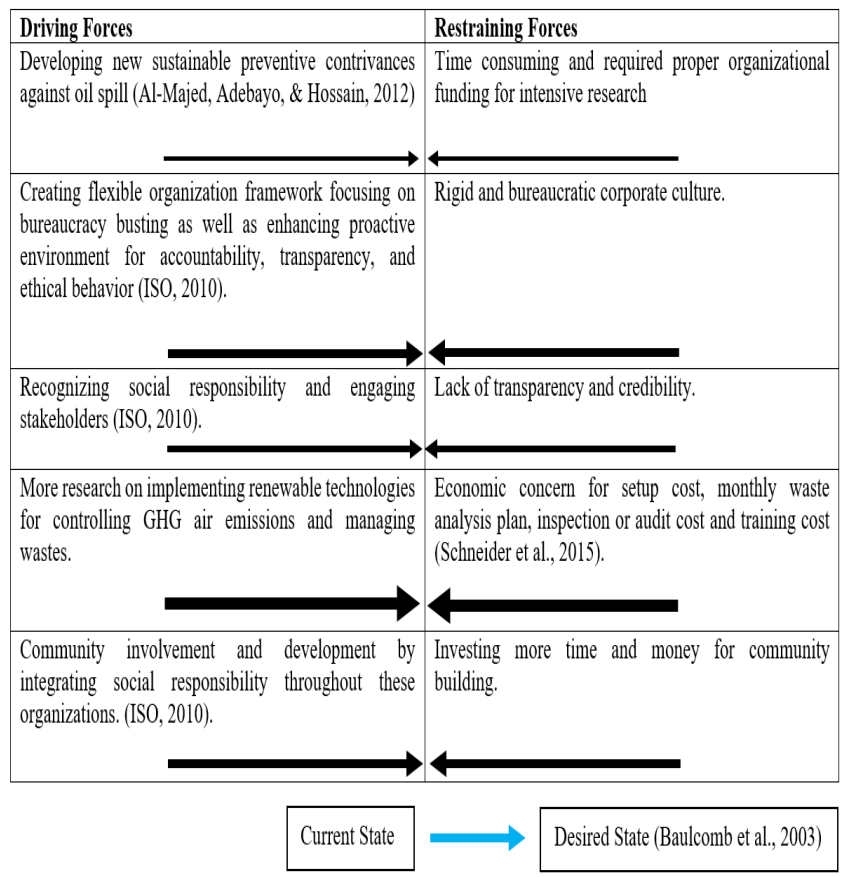

Figure 10. Force field analysis for the impact of CS and CSR in Shell, BP and Total S.A. [28]

- Engineering managers should perform hazard analysis and risk assessment frequently to avoid disasters and accidents.

- Engineering managers must be careful about the social well-being of employees and labors because social well-being is a platform of company's CSR outlook. So, the manager must deal with any conflict among personnel and he should break the traditional barrier among the departments to create an environment of transparency and credibility.

- Engineering managers should take proper steps to train specific workforces for preparedness plans for the spills and should evaluate the effectiveness of training on the worker's performance using different methods of assessment like observation, simulation, written assessment, etc. [12,29-32].

- Engineering managers should be aware of recent invention in the field of renewable technologies as mangers could suggest or adopt feasible future sustainable projects to gain a more sustainable outlook.

\section{Conclusion}

Sustainability and Corporate Social Responsibility both are imperative for today's organization because future investment and brand value of the organizations are now largely depended on the typical aspects CS and CSR. Successful implementation CSR and CS strategies are very vital for oil and gas industries due to fact that these industries are very responsible for the global environment as well as these companies represent the top wealthy industries of the world. Thus, the brand value and storytelling of these companies will influence other organizations to follow their exclusive strategies for dealing with economic oddities, environmental challenges, and social issues. The three oil and gas industries (Shell, BP, and Total S.A.) that have been analyzed in this project work, demonstrate that their CS and CSR strategies are not the same and there is scope of improvement. From the comparative analysis, BP's investment $(0.8 \%$ of the net annual profit) in community development is very low compared to the investment in community development of Shell (5.5\% of Net annual profit) and Total S.A. (4.77\% of Net annual profit) which clearly indicates that BP's CSR strategies are not sustainable also BP's TBL aspects are not balanced in this case. Although the mission and vision statement of these organizations indicate that these companies are improving on some specific CS and CSR aspects, these organizations can work more on various significant factors like 
emphasizing more on training on the workforce, industrial hygiene or health monitoring, risk analysis, hazard mitigation, community involvement and development. Total and BP both organizations are not still following any established sustainability framework to assess or evaluate their concurrent situation, but Shell maintains a framework to achieve its desired sustainability and this strategy helps Shell to acquire more brand value than other companies. Total and BP should emphasize more on building an effective sustainability framework like Shell which will help to be more sustainable and social oriented.

\section{Nomenclature}

CSR: Corporate social responsibility

CS: Corporate sustainability

SD: Sustainable development

$\mathrm{CO}_{2}$ : Carbon di-oxide

UN: United nations

BP: British petroleum

TSA: Total société anonyme

ISO: International organization for standardization

\section{Declaration of Conflict of Interests}

The authors declare that there is no conflict of interest. They have no known competing financial interests or personal relationships that could have appeared to influence the work reported in this paper.

\section{References}

[1.] Ebner, D., \& Baumgartner, R. J. (2006). The relationship between Sustainable Development and Corporate Social Responsibility. Corporate Responsibility Research Conference 2006, (September), 17.

[2.] McPherson, S. (2012). Why CSR's Future Matters to Your Company. Harvard Business Review Blog Network, 1.

[3.] International Standard Organization. (2010). International Standard Organization ISO 26000:2010, 2010, 86.

[4.] Palmer, H. J. (2012). Corporate Social Responsibility and Financial Performance: Does it Pay to Be Good?, 1-72

[5.] Hayward, R., Lee, J., Keeble, J., McNamara, R., Hall, C., Cruse, S., ... \& Robinson, E. (2013). The UN Global Compact-Accenture CEO Study on Sustainability 2013. UN Global Compact Reports, 5(3), 160.

[6.] Brundtland, M. G. H. (1988). World Commission on Environment and Development. Environmental Policy and Law, 14(1985), 2630.

[7.] Deegan, C., \& Gordon, B. (1996). A study of the environmental disclosure practices of Australian corporations. Accounting and business research, 26(3), 187-199.

[8.] Elkington, J. (1999). Triple bottom line revolution: reporting for the third millennium. Australian CPA, 69(11), 75-76.

[9.] Maas, K., \& Boons, F. (2010). CSR as a strategic activity. Louche, C./Idowu, SO/Leal Filho, W.(2010)(Hrsg.): Innovative CSR. Sheffield: Greenleaf Publishing. S, 154-172.

[10.] Crutzen, N., \& Herzig, C. (2012). Sustainability, Strategy and Management Control: A Review of the Literature, (September), 110.

[11.] Kannegiesser, M., \& Günther, H.-O. (2013). Sustainable development of global supply chains-part 1: sustainability optimization framework. Flexible Services and Manufacturing
Journal, 26(1-2), 24-47. https://doi.org/10.1007/s10696-0139176-5

[12.] Schneider, J., Vargo, C., Campbell, D., \& Hall, R. (2011). An Analysis of Reported Sustainability-Related Efforts in the Petroleum Refining Industry. The Journal of Corporate Citizenship, 44, 6984.

[13.] Schneider, J., Ghettas, S., Merdaci, N., Brown, M., Martyniuk, J., Alshehri, W., \& Trojan, A. (2015). Towards Sustainability in the Oil and Gas Sector: Benchmarking of Environmental, Health, and Safety Efforts. Journal of Environmental Sustainability, 3(3), 6.

[14.] Van Marrewijk, M. (2003). Concepts and definitions of CSR and corporate sustainability: Between agency and communion. Journal of Business Ethics, 44(2), 95-105.

[15.] Loew, T., Ankele, K., Braun, S., \& Clausen, J. (2004). Significance of the CSR Debate for Sustainability and the Requirements for Companies. Institut for Ecological Economy Research $\mathrm{GmbH}$ (IÖW).

[16.] Kaptein, M., \& Wempe, J. F. D. B. (2002). The balanced company: A theory of corporate integrity. Oxford University Press, USA.

[17.] Royal Dutch Shell. (2015a). Investors' Handbook.

[18.] Royal Dutch Shell. (2015b). Sustainability Report 2015.

[19.] BP PLC. (2015). BP Sustainability Report, 52.

[20.] BP PLC. (2016). Annual Report 2015.

[21.] Total S.A. (2014). At a Glance 2014 the Year in Figures and Pictures Message From the Ceo Our Flagship Projects for Our Customers Activities.

[22.] Total S.A. (2015). Total Sustainability Report, 28-31.

[23.] Spence, D. B. (2011). Corporate social responsibility in the oil and gas industry: the importance of reputational risk. Chi.-Kent L. Rev., 86(1), 59-85.

[24.] Al-Majed, A. A., Adebayo, A. R., \& Hossain, M. E. (2012). A sustainable approach to controlling oil spills. Journal of Environmental Management, 113, 213-227. https://doi.org/10.1016/j.jenvman.2012.07.034

[25.] Ness, B., Urbel-Piirsalu, E., Anderberg, S., \& Olsson, L. (2007). Categorising tools for sustainability assessment. Ecological $\begin{array}{lll}\text { Economics, } & 60(3), & 498-508\end{array}$ https://doi.org/10.1016/j.ecolecon.2006.07.023

[26.] Chen, D., Thiede, S., Schudeleit, T., \& Herrmann, C. (2014). A holistic and rapid sustainability assessment tool for manufacturing SMEs. CIRP Annals - Manufacturing Technology, 63(1), 437-440. https://doi.org/10.1016/j.cirp.2014.03.113

[27.] Harik, R., EL Hachem, W., Medini, K., \& Bernard, A. (2015). Towards a holistic sustainability index for measuring sustainability of manufacturing companies. International Journal of Production Research, 7543(July), 1-23. https://doi.org/10.1080/00207543.2014.993773

[28.] Baulcomb, J. S. (2003). Management of change through force field analysis. Journal of nursing management, 11(4), 275-280.

[29.] Raufflet, E., Cruz, L. B., \& Bres, L. (2014). An assessment of corporate social responsibility practices in the mining and oil and gas industries. Journal of Cleaner production, 84, 256-270

[30.] Ibrahim, Y M, Hami, N and Othman, S N (2019). Assessing of Imbalance among Economic, Environmental and Social Sustainability: Evidence from Oil and Gas Industry in Iraq, 2nd International Scientific Conference, Journal of Physics: Conf. Series, IOP Publishing, 1294

[31.] Ibrahim, Y. M., Hami N., \& Abdulameer S. S. (2020). Assessing Sustainable Manufacturing Practices and Sustainability Performance Among Oil and Gas Industry in Iraq. International Journal of Energy Economics and Policy 10(2).

[32.] Ibrahim, Y M, Hami, N and Othman, S N (2019). Integrating Sustainable Maintenance into Sustainable Manufacturing Practices and its Relationship with Sustainability Performance: A Conceptual Framework, International Journal of Energy Economics and Policy 9(4), 30- 39.

\section{How to Cite This Article}

Duttagupta, A., Islam, M.M., Rabiei Hosseinabad,E., and Zaman, M.A.U., Corporate Social Responsibility And Sustainability: A Perspective From The Oil And Gas Industry, Journal of Nature, Science \& Technology,2(2021),22-31.

https://doi.org/10.36937/janset.2021.002.004 